Euskal ikerketen aldizkaria | Revue d'études basques |

Revista de estudios vascos | Basque studies review

$9 \mid 2004$

Numéro IX

\title{
XVIII mendean Jean Espil-ek zubereraz moldatu Jean Racineren Esther
}

\section{Patri Urkizu}

\section{OpenEdition \\ Journals}

Édition électronique

URL : http://journals.openedition.org/lapurdum/885

DOI : 10.4000/lapurdum.885

ISSN : 1965-0655

\section{Éditeur}

IKER

\section{Édition imprimée}

Date de publication : 1 novembre 2004

Pagination : 311-320

ISBN : 2-68781-376-X

ISSN : $1273-3830$

Référence électronique

Patri Urkizu, «XVIII mendean Jean Espil-ek zubereraz moldatu Jean Racineren Esther », Lapurdum [Linean], 9 | 2004, Sarean emana----an 01 mars 2009, kontsultatu 19 avril 2019. URL : http:// journals.openedition.org/lapurdum/885; DOI : 10.4000/lapurdum.885 


\title{
XVIII mendean Jean Espil-ek zubereraz moldatu Jean Racineren Esther
}

\author{
Patri URKIZU \\ UNED
}

Esther hitzak "Izarra" esan nahi du hebraieraz, eta Testamentu Zaharreko liburu bati izena ematen dion heroia da. K.a. II. mendean idatzia, Estherren ixtorio honek erbestean ziren kolonia juduen zinak eta minak, gora-beherak eta fatu beltza oroitarazten ditu. Alegia, Persiako errege zen Zirusek (K.a. 538) Palestinara itzultzeko baimena eman ondoren inperioan sakabanaturik gelditu zirenen zoria, zein batzuentzat on eta besteentzat gaizto gertatu zen, hauei eraso bortitzik pairatzea suertatu baitzitzaien.

Bibliak dioena laburbilduz, Assuerus erregeak Indiatik Etiopiaraino gobernatzen zuen garaian gertatu zen, -hau historialariek Xerxes, Zirusen iloba dela diote, zeinaren untzi-flota Salaminan suntsitu zuten Temistokleren ontzi hiruarraunlerrodunek-. Antza denez, estratega eskas hau adituago zen haremeko andereen kontuetan soldaduenetan baino. Hala, egun batez bere emazteak berritzearren agindu zuen erresuma osoko neskatxarik ederrenak bil ziezaizkioten. Hauen artean agertu zen bat besteak baino xarmangarriago, Esther izenekoa, Mardokea judu zuhurraren iloba, - hebraierazko bertsioan lehengusua, Vulgatan osaba -, zeina hautatu zuen erregek erregina izateko, honen eragina senarrarengan gero eta handiagoa gertatu zelarik.

Mardokea zuhurrak ilobari gomendatu bide zion leinua ez zezan aipa, zeren eta bere herriari zerbitzu handirik eskaini behar zion etorkizunean. Bidenabar Mardokeak erregeari beste zerbitzu handi bat eskaini zion konplot bat salatuz.

Garai hartan aski hedatua zegoen antisemitismoa lurralde haietan eta Aman ministrari amalezita zen juduen etsairik gogorrena, bide batez juduen kontrako dekretua sinarazi ziolarik erregeari. Orduan Estherrek bere etorkia aitortu zion Asuerusi, eta hain izan ziren erabilitako hitzak zuhurtasunez beteak, eta batipat hain izan ziren bere begiak eta irudia erakargarriak, non malkoek eta hitzek aurkitu baitzuten erregearengan kupida eta oihartzunik. Areago, ez zuen soilik aurkitu salbazioa bere arrazako juduentzat, baizik eta aukera eman ziola sarraski ikaragarria burutzeko Aman eta honen kastakoengan. Eta pozik ez zelarik egindako hilketekin, ikusten ahal da Esther ezti, apal eta xarmanta eskatuz kontrapogromak oraindik hogeitalau ordu luzez jarrai dezan.

Honela ikusten da zein bidetarik jainko guztiz ahaldunak babestu zuen bere herri hautatua, eta bide batez Israelen Purim deitu jaian Estherren ixtorioa oroitzen da. 
Purim, hots, zotzaz edo noiz suertatuko zen Amanek pentsaturik zeukan sarraskiaren eguna, zein gertatu zitzaion berri alderantzizkoa, zehatzago esanez, tragikoa.

Hona Bibliako ixtorioaren laburpena. Badira, ordea, bertan aipatu ez diren xehetasun zenbait merezi dutenak ene uste apalez ezagutzea, Gabriel Cohen ${ }^{1}$ irakasleak beste irakurketa interesagarria egin baitigu. Hona dioena.

Dakigunez, Vashti deitzen zen Asuerus erregearen lehen emaztea. Erregeak bere gortesauei bankete eder bat eskaini zien, erreginak jauregian bere haremkideei oturuntza oparoa eskaintzen zien bitartean. Erregeak nahi izan zuenean, ardoak eraginda, bere emaztearen edertasuna gortesauei eta herriari erakutsi eunukoak igorri zituen erreginagana agindua bete zezan, baina hau ukatu egin zen. Asuerus, orduan, kolera handi batek hartu zuen.

Ezezko erantzun hau dela eta, alegia, jendaurrean biluztera ukatzeagatik kontsideraturik izan da Vashti lehen feminista bezala. Vashtiren portaerak gizonen estatutua eta garaitasuna erresuman kolokan jartzen zuen eta horregatik, - beste andereek Vashtirengan ikusiko baitzuten beren askatasunaren eredua -, erregearen agindu batek erregina bere tronutik bota zuen eta erabaki beste emakume baliagarriagoa hartzea.

Gutunak bidali zituen bere erresumako bazter orota ra, hizkuntza eta letra berezietan, jendaki bakhotchak adi eta irakur izan ahal zezan, senharrak buruzagi eta na usi zirela beren etchetan; eta hori oihu-egina izanen zela populu guzietan. ${ }^{2}$

Honek bi gauza adierazten zituen argi eta garbi. Lehenik, gizonak agintzen zuela etxe barnean, eta bigarrenik, berak erabakiko zuela etxeko kultur bizitzaz eta erlijio heziketaz hala nola familiaren egituraz. Nabarmen dago, beraz, dekretu honek zuen helburua, - andereen botereaz beldur baitziren nonbait gizonak -, eta lege neurriak hartu zituzten beren andereengan aginte absolutua ezartzeko asmoz.

Erregina berriaren hautaketa, egun ere hain modan dagoen zein ederrago konkurtsoaren bitartez egin zen. Dena den, hamabi hilabete igaroko dute beren buruak prestatzen (sei mirrazko olioaz gantzutzen, eta beste sei pote usain ondunez eta baltsamuez baliatzen ikasten, Est. II, 12). Mardokeak, bada, borondatearen kontra eramaten du Esther errearengana, eta Asuerusek haren edertasunaz guztiz liluraturik erreginatzat hautatuko du.

Amanek, ordea, dakigun bezala ez zituen begi onez ikusten juduak eta hori dela eta agertuko da Estherren misioa, hots, Jainkoak aukeratu izanaren zioa eta arrazoia.

Cohenek Estherrengan bi portaera bereizten ditu. Bata, erregearekiko zituen harremanak. Oso gutxitan deitua omen zen zegozkion emazte funtzioak betetzera. Hots, mirabe gisara. Eta bestea, judu izaerarena, non ez dagoen besteen aginduetara, beraxe baita aginduak ematen dituena. Hala, Mardokeari agintzen dio barau egin dezaten judu guztiek hiru egunez, berak, erreginak, eginen duen legez. Ondoren aurkeztuko zela erregearengana, - deitua izan gabe ezin ziteekena egin -, eta gerta zedila gertatu beharrekoa, hau da, Jehovak gogoko zuena.

Antze, jakituria eta fantesiaz betea zen Estherrek badaki erregea jelosiaz betetzen eta Amanen kontra ezartzen, eta hau, etsai amorratua bailitzan aurkezten. Beraz, urkabera eramaten.

1 - Gabriel Cohen , "Le féminisme dans le livre d'Esther", www.jajzd.org.il/french/fetes/pourim/ivre/articl/art 1.html. 2 - Esther, Kap. I-22, Duvoisinen itzulpenaz, 1860, 517. 
Ez zaio, ordea, Esterri askiesten erret-agiria deuseztatzeaz, beste bat idazten baitu, non Susa hiriburuan bostehun gizon eta Amanen hamar semeak hil ondoren, mendekiozko egun bat gehiago eskatzen dio erregeari lurralde osoko juduen etsaien deusezteko, akabatzeko eta suntsiarazteko.

Konforme oraindik ez, eta bi gutunen bidez Mardokea eta Estherrek agintzen diete mundu zabalean barreiaturik dauden judu guztiei oraindaino egun ere ospatzen den Purim deitu jaian oroit daitezen aurrerantzean ekintza hartaz.

$$
* * *
$$

Erdi Aroan Misterioetako pasarte eta ekintza asko inspiratu zituen Bibliak, eta bereziki Frantzian XV. mendean idatzi zen Le Mystère du Vieil Testament, hots, Testamentu Zaharreko Misterioak. Hemen beste ixtorio askoren artean Estherrena ageri da nabarmen. Parisen antzeztu zen eta 1540an moldiztegiratu misterio luze horretan Histoire de Hester delakoa, XXII ixtorioa, 44.326 eta 46.373 bertsoen artean ageri da, beraz, 1947 bertsolerro dituen misterioa.

Ohikoa zen bezala frantsesa latinareki nahasten zen eta hala Asuerusen morroi zen Baratha delako batek dio : Assuaire a ung peit beu / Bien voy, incaluit vino. ${ }^{3}$ Alegia, pixkat edan zuela eta ardoak berotu egin zuela.

Espainian Lope de Vegak La Bella Esther (1610) idatzi zuen modu aski sinplean, zeren pertsonaia nagusia ageri duen Probidentziaren erramintza legez bere herriaren salbatzeko, baina tragediaren arrazoi pertsonal sakonak aztertu eta arakatu gabe. XVII. mendean ere Felipe Godinez antzerkigile sebillanoak idatzi zuen Aman y Mardoqueo, ó la horca para su dueño (ó la Reina Esther).

Italian Federico de la Valle idazleak Esther (1627) burutu zuen, non hau emakume xarmangarri eta malenkoniaz betea bezala ageri zen.

Alemanian Luterok jada bere Biblia liburuen hitzaurrean (1534) adierazten zuen ezin aproposagoak zirela Judith, Esther, Tobias, Daniel edota Susana bezalako pertsonaiak beraietaz antzerkiak burutzeko, eta honen ideiei jarraiki Thomas Kirchmaïer idazle protestanteak Esther idatzi zuen (Bâle, 1546), zein eskola protestanteetan antzeztarazi ohi zuen. Gaztediari garaiz behar omen zitzaion txertatu bihotzean tirania papistaren kontrako gorrotoa.

XVII eta XVIII. mendeetan Oratorio anitz, hots, musika lan ugari sorrarazi zituen ere gaiak, eta hala Pietro della Vallek (1640), Alessandro Stradelle (1679) eta Georg Friedrich Haendel berak (1720-32) , - honek lehen aldiz ingelesez-, edota Edelmannek (1781).

Bere aldetik Frantz Grillparzer, antzerkigile austriarrak XIX. mendean burutu Esther lanean (1863) beste ikusmolde erabat ezberdina plazaratu zuen. Judutarren mesianismoa pertsonifikatzen duen Mardokea fanatiko bisionarioan aitzinean zentzu arruntarena irudikatzen duen Estherrena kontrajarri baitzuen. Honek dudatan jartzen zuen Jainkoak bere begiak ezar zitzakeenik, interesa zitekeenik herri batean edo bestean, eta kezkatzen da fanatismoarekin eta jainkoak hautatu herriekin. Beraz, Esther honen arabera emakume ezti eta arrazointsu bezala ageri da, mistika gogoetarik gabea.

XX. mendean gaurkotze eta eguneratze ugari izan ditu ere. Adibidez, Armand Lunel eta Darius Milhaudek moldatu Esther de Carpentras obra, non Esther aktoresa

3 - De Douhet, Dictionna ire des mystères... Ed. Abbé Migne, Turnholti, Belgium, 1854, 1021. 
judu xarmangarriak Midi aldeko herrixka batean apezpikua liluratzen du, honela eragotziz eliz-gizonak sinaturik zeukan erbesteratze eta kontzentrazio zelaietarako agindua heda eta bete zedin.

Salvador Espriu idazle katalanak bere aldetik 1948an Primera Historia d'Esther (1948) idatzi zuen analogia bat eginez frankismopean zegoen herri katalanaren eta juduaren artean. Donostian ere ikusi ahal izan genuen 1968an, Ricard Salvaten zuzendaritzapean.

Pinturan eta musikan esan bezala izan zuen ere adierazlerik, hala XII. mendeko Souvingyko Biblian, XV. mendeko Jean Manselen Fleur d'Histoires-en, XV-XVI pintore italianoetan (Mantegna, Michel Angelo, Veronese...)...

Frantzian Jean Racinek (1639-1699) Esther 1689an aurkeztu aurretik, izan zituen gaiak aitzindaririk teatroan, misterioaz at. Hauen artean, André de Rivaudeau-k bost ekitalditan eta bertsotan moldatu Aman (1566), Pierre Mattieu-ren Esther (1578), obra txit luzea, Antoine de Montchrestien-en Aman ou la verité (1601), non Estherren pertsonaia zertxobait geroxeago Pierre du Ryer-ek 1644ean plazaraturikoarekin konparatuta aski ezberdina zen. Montchrestien-en Esther neskatxa xume gisa ageri zaigu eta bere xumetasunean edireiten du ausardia eta kuraia bere helburua lortzeko. Ryer-enean, aldiz, emakume harro eta fier bezala ikusten dugu. Bakarrik porrotaren beldur dena. Halaber Felicien du Saint-Esp delako antzerkigileak Parisen antzeztarazi zituen bere Judith-a (1654-II-7) eta Esther (1654-II-15).

Racineren obra Biblian ageri den ildotik doa. Jainkoak Ester erreginatzat hautatu eta Asuerusen bihotzean du kokatu, haren eztitasunak, apaltasunak eta beste kalitateek purpurak eta urreak baino gehiago balio baitute.

Esther, Maintenongo Madamak ${ }^{4}$ Racineri eskatu eta honek Saint-Cyr-eko neskatxek errepresenta zezaten moldaturiko antzez-lana da. Hasieran ez zeraman tragédie titulua, ouvrage de poésie tiré de L'Écriture Sa inte, propre à être récité et à être chanté, baizik. Hots, idazki sainduetarik hartu eta poesia lana errezitatzeko eta kantatzeko aproposa.

1685ean sortu Saint-Cyr-eko Ikastetxean 250 gazte, noble eta pobre bizi ziren eta hauentzat Maintenongo Madamak heziketa serio bezain alaia zuen gogoko. Horrela hauen atsedenaldietarako prestatzen zituzten antzezkizunak, poema moral edo historikoak, nondik amodio kontuak erabat ezabatuak zeuden.

Racinek enkargua hartu eta historiografo lanbideari astia kenduz urte batean burutua zeukan antzerkia, zein jada argitaratu beste tragedia grekoen ereduari jarraikiz moldatu zuen. Beraxek zuzendu zituen antzezleak, deklamatzen erakutsiz, Boileau adiskidea eta musika zatiak konposatu zituen Moreau, Saint-Cyr-eko organistaren lagun izan zituelarik.

Lehen ikuskizuna, estreinaldia, erregearen aurrean eman zen 1689ko urtarrilaren 16an. Dena zegoen prest eta gertu arrakasta lortzeko. Dekoratuak, - Borin korteko

4 - Françoise d'Aubigné, Maintenongo markisa (Niort 1635 - Saint-Cyr 1719), Agripa d'Aubignéren iloba, kalbinismoan hazia, diru egoera kaxkarragatik Scarron poetarekin ezkondu zen, eta honela Sévignéko Madamaren eta La Fayette madamaren korte aberatsean sartu zen. Senarra hil zenean, dirurik gabe Louis XIVaren haurren heziketaren ardura hartu, eta Marie Thérèseren hilketaren ondoren sekretuki Louis XIV-arekin ezkondu zen, korteari aire seriosa emanez. Erregea hil zenean 1715ean fortunarik gabeko etxe nobleetako alaben heziketarako eraiki zuen Saint-Cyr-eko jauregira erretiratu zen. 
dekoratuen pintoreak eginak -, jantziak - hauek perla preziosez eta harri ederrez hornituak -, erregeren musikariak koroaren lagungarri, eta beste.

Ikusleen artean, erregeaz aparte, Dauphina, Louvois, Bossuet zeuden, hala nola antzezten parte hartzen ez zuten berrehun neskatxak, denak urdin jantziz eta boneta xuriz bestituak.

Arrakasta, beraz, handia izan zen eta hamabost urteko Veilhannes andereño xarmantak Esther jokatu bazuen lehen aldian, bigarrenetik Caylus Madama izan zen bereganatu zuena protagonistaren rola. Gainera, hain izan zen handia arrakasta non soberaxkoak iruditu zitzaizkion apezpikuari neskatxek errezibitzen zituzten txalo eta laudorioak, eta hauek arimaren bakerako kaltegarri eta asaldamendurako bide izan zitezkeela eta errepresentazioak etenarazi egin zituen agintari erlijiosoak.

Hogeita hamar urtez antzeztu gabe egon ondoren Esther, 1721eko maiatzaren 8 an jokatu zuten Fossés-Saint-Germain kaleko komediagile profesionalek errege ordearen baimenaz honen antzokian. Hau da lehen aldiz ikusle edonorentzat, denentzat idekia. Baina, jada kantuak kenduak ziren eta koroetako bertso batzu soilik gelditu ziren, eta itxaroten zen lehen aldietako emankizunen arrakastak porrot egin zuen. Harrera nahiko hotza izan zuen, beraz.

Dena den XVIII. mendean antzerkiak lau argitaraldi baino gehiago izan zituen, eta 1680az geroztik 1936rainoko bitartean 192 emanaldi izan zituen. Hauen artean Odéon eta Comédie-Française-ren antzokietan emandako antzezkizunak gertatu ziren famatuenetarikoak.

Historian zehar Esther jokatu zuten aktoresen artean ospetsuenetarikoak hauexek izan ziren : Marie Desmares, Champmeslé deitua eta Racineren amorantea, Duclos andereñoa (1670-1748), famatua bere ahots ezti, zoragarri eta harmoniaz beterikakoaz ; eta Duchesnoi andereñoa (1777-1835), kalitate berekoa eta modu elegiako bereziz antzezten zuena, Rachel (1839), Sarah-Bernhardt (1905) andereek soilik burutu antzezkizunean Assuerusen rola egin zuena.... Baina aktoresa zenbait ohartuz Racineren obrak ez zuela fideltasun osoz jasotzen Bibliakoa, ez zuela islatzen zehatz-mehatz hango Estherren irudia, beren ikusmolde propioa erantsi nahi izan zioten. Bidenabar Colona-Romano andereak (1925) pertsonaia konplexu bat sorrarazi zuen : eztia, liluragarria, xarmanta, baina bere birtuteez at beste xarmak ere erakusten saiatzen zen, eta Amanekiko furia, gogorkeria eta bortitza benetan izugarriak ziren.

Racine iturrietara eramaten zen berriro, baina argi eta klarki haren ikuspunduari tradizioa eginez.

Annie Ubersfield ${ }^{5}$ kritikariaren iritziz, Racineren obran koroek operarantz hurbiltzen dute tragedia, eta zehatzago esatearren, areago lirudike Esther oratorio bat tragedia baino. Racineren hizkera harmoniaz betea, xit musikala da, eta poesia hizkuntzaren ahalmenak oro trebeki darabilzki : izen propioen eztia, erritmoa, aliterazioak, barne errimak... benetan obra miresgarria da.

Bestalde, ez da Racinerengan Corneille baitan bezala heroi feodalen laudorio eta goraipatze gehiegixkorik, zeren eta eratu ordenaren kontra asaldatu gabe, handi eta ttipien arteko borrokan ez den garaile gelditzen tiranoa, aldiz, ttipia batzuetan ia deuseztatua dela iruditu arren azkenean irabazle irtengo da. Beraz, tragedia

5 - Annie Ubersfeld, “Racine (1639-1699), Histoire littéraire de la France, T. II De 1600 à 1715, Ed. Sociales, Paris, 1966, 294-319. 
racineanoa bortizkeriaren ezetza eta balio moralen baietza, tiraniaren aurka eta justiziaren alde dago. Baina halere, Racine aski ezkor, kezkati eta zalantzaz betea da, bere garaiko burgesiaren ispilu. Hona bada Estherren eta Racineren obran orokorki ageri diren bi ezagugarri : giza ezkortasuna boterearen aurrean eta justiziaren gosea, zorionarenganako jaidura nostalgikoa. Hau dela eta Racine sentimenduen eta boterearen pintore handienetarikoa dugu, eta hain izan zen estimatua non anitz itzulpen izan zituen bere obrak. Hala :

Holandesez : F. Ryck, Hester of de verlossinge der Joden, Treurspel, (Amsterdam, 1719)...

Alemanez : J. Chr. Bröstedt, Esther (Lüncburg, 1745)

Ingelesez : J. Mois, The sacred dra mes of Esther... (Edimburg, 1803)

Hebraieraz : J.J. Rapport, Esther (1827)

Gaztelaniaz: C. Gibert y Futo (ed.), Tragedia de Esther (Barcelona, s. XVIII)

Katalanez : Miquel Ribes (1731-1799).

Eta ez zen euskarazko moldaerarik ere faltatu tamalez gaur egun arte argitaragabe egon dena, lehenik Campan-Latsague familiaren bibliotekan eta gero Baionako Euskal Museokoan.

Itzulpena badirudi eskuzkribuko bigarren orrian dioen bezala, Espil de Mendi delako batek egina litekeela.

George Hérelle-k dioenez " $13^{\circ}$ Esther. Particulier. Ca mpan-La tsa gue... 26 feuillets... environ 570 versets subsistants. XVIII siècle. ... La source immédia te de cette pastorale est la tragédie de Racine, que le pastoralier a imitée plutôt que traduite, en la ramenant à la forme archä̈que d'un mystère. Aucune représentation connue. ${ }^{6}$

Eta eskuzkribuaren aitzin orrian beste honakoa ageri da idatzirik : C'est la tra gédie de Racine, ma is remise en forme de mystère par le pa storalier. Seule pastorale ba sque qui soit imitée du théâtre classique".

Ez dugu uste hau oso zehatza denik. Alde batetik ez da misterioen eran antolatua, Racineren Piété delako irudiak egindako sarrera hemen, hori bai, entrada gisa antolatua dago. Beste dena ez da Racineren itzulpen zuzena baizik, batzuetan laburtuz. Ez dago ez batailarik, ez sataneriarik, ez ohikoak direnak beste pastoraletan.

Hona zehazki bertsoen kopuruen berri :

\begin{tabular}{|c|c|c|c|c|}
\hline & Prologue /Entrada & I Ekitaldia & II Ekitaldia & III Ekitaldia \\
\hline Racine & $70 \mathrm{~b}$. & $372 \mathrm{~b}$. & $825 \mathrm{~b}$. & $1286 \mathrm{~b}$. \\
\hline Espil & $132 \mathrm{~b}$. & $422 \mathrm{~b}$. & $824 \mathrm{~b}$. & $1188 \mathrm{~b}$. \\
\hline
\end{tabular}

Eszenak, agerraldiak eta ekitaldiak ez daude markatuak, soilik pertsonaiaren sarrera dago seinalatua, eta antzez-oharrak frantsesez daude.

6 - G. Hérelle, Catalogue sommaire de toutes les pastorales connues à ce jour. Imprimerie Nationale. Paris 1922. 
Eskuzkribuak ez du tamalez 25 folio baizik, antza denez azkeneko biak edo falta direlarik, VIII eta IX agerraldiak gelditzen direla itzultzeke.

Beraz, Hérellek ${ }^{7}$ berak aipatzen duen eran pastoralegile baten hitzak jasoz, Je lis le livre; puis, quand je vois quelque chose de joli pour la pièce, je le compose. Alegia, liburua irakurtzerakoan zerbait interesgarririk topatzen bazuen huraxe moldatzen zuela, eta azpimarratzen du Hérellek halaxe egiten zutela ere XV. mendeko misteriogileek.

Euskararen moduari dagokionez, hona zer zioen Boissel-ek ${ }^{8}$ aditu zuberotar bati kontsulta egin eta gero :

L'opinion d'un érudit souletin qui a examiné l'ensemble de la collection est qu'il s'y trouve nombre de pastorales écrites en un assez bon basque et que quelques unes, notamment celle d'Esther (adaptation de l'Esther de Racine, faite apparemment par un prêtre qui a ramené la tragédie classique à la forme du Mystère), sont même en un basque excellent.

Noizkoa ote da Espilen itzulpena ? Eta noizpait antzeztu ote zen ?

Balirudike konparatuz zubererazko beste testuekin XVIII. mendeko lehen partean idatzia izan daitekeela. Hala, Tartasek (1666) eta Belapeyrek (1697), gure eskuzkribuak bezala, - qui, ore, eta derit (dirit, Esther), erabiltzen dute eta aldiz Beñat Mardok (1757) eta Maisterrek (1757), -ki, hire, eta deit, grafema, izenlagun posesibo eta aditz laguntzaileen forma berriagoen aurrean.

Honelaxe nioen Pabeko Archives Departamentales delakoetara joan aitzin Espil Mendiarraren azternen bila. Galdetu nuen hemen eta hona hiru agirietan aurkitu nuena Espilez :

1762 Lan mil sept cent soixante et deux et le vingt et trois... a pres a voir publiés les bans du futur ma riage dentre Etienne Carricart demeurant Chera ute et Ma rie Laso loca taire a la place... j'a i Marc Basterreche pretre et curé d'Ida ux et Mendy imparte la benediction nuptiale aux susdits Etienne Carricart et Marie Laço aiant observé les ceremonies de la Ste église en presence d'Aramd Mesplez et Michel de Bidart, Jean d'Espil et Bernard D'Escarain ces deux derniers maitres d'école l'un a Idea ux, l'a utre Mendy qu'ont signé avec moy non les deux a utres pour ne scavoir écrire de ce requis, par moi Basterreche curé, Espil, Escara in. ${ }^{9}$

Beraz, badakigu izan zela Jean d'Espil bat Mendikoa, eta maisu zena. Beraz ez dirudi hipotesi burugabea pentsatzea beraxe izan zela Racineren itzultzailea. Baina noiz ote zuen itzuli ? Hona beste heriotza agirien artean aurkitua :

1786 L'an mil septcent quatre vingt six et le six novembre est décedé Jean Espil agé d'environ quatre vingt cinq ans, apres avoir reçu les sacrements de penitence, eucharistie et extreme unction, son corps a été inhumé le lendemain a u cimetière de l'église avec les ceremonies ordinaires en presence d'Oserang et Etchart les deux de Mendy qui n'ont signé pour ne savoir ecrire de ce requs. Pour moi Basterreche curé.

Beraz, 1701ean jaio eta 1786an hil zen gure Mendiko errejenta izan zen Jean Espil. Ez dakigu jaiotze data zehazki agiriak 1743an hasten direlako. Badakigu, ordea, bere

7 - G. Hérelle, "Les sources des Pastorales et la Méthode de travail des Pastoraliers”, Gure Herria , Baiona, 1922,701

8 - W. Boissel, “Notices pour l'établissement d'un catalogue (le fond Campan-Latsague)", Bulletin du Musée Basque, Bayonne, 1926.

9 - Archives Départementales de Pau. Idaux-mendy 1743-1791. 5 Mi 268. 
emaztea daitekeen Marie Aroix, maitresse vielle D'Espil, urte berean, hilabete berean eta Jean baino hiru egun beranduago hil zena.

Lehen atera dugun hizkera kontuei buruzko datekin bat datoz agiri hauek, ondoriozta dezakegularik, maisu izan bazen 20-30 urtekin, eta gazterik eman ziola itzultzeari, eta erabili edizioa 1721ekoa izan zitekeela, bada hortxe-hortxe, esan bezala XVIII mendeko lehen partekoa daitekeela itzulpena.

Noizpait antzeztu ote zen galdetzen dugu, eta Hérellek dioenez ez da ezagutzen errepresentaziorik. Hala da, ez dugu batere berririk honetaz, baina izan zitekeen antzeztua. Agian Mendin Espilen herrian bertan, edota agian Frantzian barrena ohiko izan zen bezala monjetxeren batean edo neskatxen heziketarako eraiki ikastetxeren batean.

Itzulpen-moldaketan garbi dago frantsesaren eragina hiztegi mailan, hala aurki ditzakegu honako maileguak, batzuetan gordin-gordinak besteetan zertxobait euskaratuak : apaisatu (baketu), aquisitu, aquitatu, arresta, autenitu, balaq, bonura, brisatu, cacheta, carnagia, comblatu, comblot, cometitu, coumant, congita, creinta, en cas, en fin, esprabatu, estranger, fabori, festi, iboignatu, irous, Ma sur (ene ahizpa), Monseignur, moustra, oragia-ora ia, perdespit, perfida, potença (urkabera), pusa nta, rejeta tu, rejouissa nça, sa geça, sa geta rçun, sependant, sira, sonja tu, sourça, susmis, troublatu, visage,....

Ez du halere euskal sena galdurik eta euskara barne-barnetik zerabilela argi dago ondorengo adibide batzuek argi eta garbi adierazten duten bezala :

Izenak :

Racine, bl. $1036 \quad$ Ah! de quel coup me percez-vous le coeur!

Espil, b. $520 \quad$ Uduri citaçu lança colpu batez bihotça igaren deitaçulla

Racine, bl. $1154 \quad$ Va, trâttre, laisse-moi.

Espil, b. $568 \quad$ Ichil adi ingoiti, coqui traidoria.

Izena ikusten dugunez indartu egin da zehaztasun haboro emanez (colpu $>$ lança colpu ; traître > coqui traidoria...) edota errepikatuz ondoren ikusten dugun bezala :

Racine, bl. 1138

Espil, b. 558

Racine, bl. 560-561

Espil, b. 365

Racine, b. 942

Espil, b. 494
Ciel, daigne m'éclairer

O celia, celia, çuq argui neçaçu.

Sans se plaindre de vous ni de sa destinée,

Il y traîne, Seigneur, sa vie infortunée.

Bere fortuna tristiaz ardura duçu plagnitcen,

Eta beha nounti edo noula reconpenxa dian uchenen.

Je ne sa is si ce tigre a reconnu sa proie

Cha npoti uduri diçu açhouri emia,

Bena bihotça crudellago eciez eta tigria.

Azken honetan garbi dago ez zaiola askietsi tigrea aipatzearekin mendiarrari eta kontrajarri behar izan duela irudia biziagotzearren axuria. Ikus ditzagun orain nola itzultzen dituen bi izen-lagun (misérable, enfanté) eta bi aditz (se glacer, voler) : 
Izen-lagunak :

Racine, bl. 1156

Espil, b. 570

Racine, bl. 1086

Espil, b. 543

Aditzak :

Racine, bl. 145

Espil, b. 207

Racine, bl. 187

Espil, b. 221
Misérable, le Dieu vengeur de l'innocence...

Ichara adi, malerousa, eguinen dia afronteriaz...

Dans le fonds de la Thrace un barbare enfanté

Barbarouetariq jalqui den houra gin da goure troublatcera

Juste ciel! Tout mon sang dans mes veines se glace. Çainetan barnen citadaçu odola oro gatçaten.

Le temps vole, et bientôt a mènera le jour Thempora badouaçu eta orenaq dira cario.

Interesgarria da ere ikustea nola eta zein dotore darabiltzan toka eta nokako adizkerak, gizarte maila ezberdin eta gizonen edo emakumeen artekoen elkarrizketetan. Adibidez, Amanek Hidasparekin hitz egiten duenean, edota Estherrek Ellisarekin :

Aman :- Hori erraiten deitada ca ni niçan estatian ?(Espil, b. 316)

Ester: - Bena othoi, Ellisa, erran içadan eguia. (Espil, b.71)

Ester.- Ba ta q çutugna odol ecina go handitariq. (Espil, b. 88)

Halaber -te orainaldiarekin gero zentzua adieraziz aurki dezakegu maiz, hala zirate, izanen zara-ren ordez:

Espil, b. $479 \quad$ Mendecatu cirenian ahatceren çaitçu oro Pha usian cirate ecinago guero.

Batzuetan testuan ageri ez dena ere eransten du, azpimarratzeko indarrez poetak esan gogo duena. Hona hiperbole eta pertsonifikazio bitxia :

Racine, bl. 717-718 Vous avez vu quelque ardente colère Allumait de ce roi le visage sévère.

Espil, b. 437 Erregueren colera handia eta visage seberoua Uduri ça it loxa çuquiala herioua.

Errefrauarik ere ez da falta etorkizko testuan ez izanik ere, adibidez, dioenean :

Espil, b. 477

Desohoure laburra hobe della eciez da mu lucia. Monseignur, niq badit sorthuz gueroz ençutia.

Ez da ikusten dugunez, hitzez hitz, hertsiki orijinalaren morroi, hizkuntza berak ematen dizkion bideak eta ahalmenak baititu oso trebeki erabiltzen. Aske, baina era berean orijinalaren zentzua ongi mantenduz, errekreatuz baina errespetatuz, itzulpena denok dakigun bezala ona bada beste sormen lana baita.

Dudarik gabe, beraz, Jean Espil (Mendy 1701-1786), bere sorterriko errejenta, XVIII. mendeko euskal itzultzaile eta idazle zahar aurkitu-berria dugu. 


\section{Bibliografia}

- MS n ${ }^{\circ}$ 2. Fond Campan-Latsague. Baionako Euskal Museoa.

- BARNWELL, H.T., The Tragic Drama of Corneille and Racine. Clarendon Press. Oxford 1982.

- BARTHES, R., Sur Racine. Paris, Seuil 1967.

- BOISSEL, W. “Notices pour l'établissement d'un catalogue (Le fond CampanLatsague)", Bulletin du Musée Ba sque, Bayonne, 1926.

- COHEN, G. "Le féminisme dans le livre d'Esther", www.jajz-ed.org-il/french fetes/pourim/ivre /articl.

- CHABOT, H. (ed.), Racine, Esther tragédie. Larousse. Paris 1954.

- DE DOUHET, Dictionnaire des mystères... Ed. Abbé Migne, Turnholti, Belgium, 1854.

- DUVOISIN, J., Bible Sa indua. Londres, 1860.

- HÉRELLE, G., Catalogue sommaire de toutes les pastorales connues à ce jour. Imprimerie Nationale. Paris 1922.

- LAFFONT-BOMPIANI, Dictionnaire des personnages de to us les temps et de to us les pays. Robert Laffon, Paris, 1960, 354-356.

- MAURIAC, F., Vie de Jean Racine. Paris 1928.

- MESNARD, P., OEuvres de J. Ra cine. Paris, Hachette 1865.

- NAÑEZ, E. \& AZPITARTE, J.M. (ed.), Jea n Ra cine. Tea tro completo. Ed. Nacional, Madrid, 1982.

- ORCIBAL, J., La genèse d'Esther et d'Athalie. Urin, Paris 1950.

- PIEJUS, A (ed.), Esther, tragédie de Jean Racine. Intermèdes de Jean-Baptiste Morea $u$, Musica Gallica. Paris, 2003.

- RACINE, J., Esther, tra gédie tirée de L'Écriture Sa inte. Denys Thierry, Paris 1689.

- UBERSFIELD, A., "Racine (1639-1699), Histoire littéraire de la France. T. II De 1600 à 1715, Ed. Sociales, Paris, 1966, 294-319. 